\title{
Lung metastases from a primary hepatocellular carcinoma
}

\section{HONEYBOURNE}

From King's College Hospital, London

\section{Case report}

A 58-year-old male insurance agent complained of a six-month history of weight loss of $12 \mathrm{~kg}$, together with dyspnoea on exercise and a productive cough for one month. He gave no history of haemoptyses, nor of abdominal or chest pain. He smoked 40 cigarettes per day but had only a moderate alcohol intake. On examination he appeared to be a wellbuilt man, but he had clubbing of the fingers, bilaterally reduced chest expansion and fine inspiratory crackles at both lung bases. The liver was grossly enlarged and irregular. The tip of the spleen was just palpable. No other abnormalities were found on examination.

Investigations showed a haemoglobin of $13.4 \mathrm{~g} / \mathrm{dl}$, a normal white cell and differential count, and an ESR of $87 \mathrm{~mm} / \mathrm{hr}$. Liver function tests detected an alkaline phosphatase level of $421 \mathrm{IU} / 1$, and a gamma glutamyl transferase level of $402 \mathrm{IU} / 1$. The chest radiograph (fig 1) shows widely disseminated amorphous ill-defined circular shadows ranging in size from pinpoint to approximately $1 \mathrm{~cm}$ in diameter. An EMI computerised tomogram (fig 2) showed these shadows to be particularly dense in the posterior part of both lung fields, and also revealed a paravertebral mass at the level of the eighth thoracic vertebra, with associated rib erosion. The CAT scan of the liver was technically unsatisfactory.

The serum alpha fetoprotein level was $7 \mathrm{ng} / \mathrm{ml}$ (diagnostic levels $>10 \mathrm{ng} / \mathrm{ml}$ ) and Australia antigen screening was negative. A technetium-99m liver scan showed hepatomegaly and a mass involving the inferior border of the liver. Ultrasound showed changes suggestive of a large homogeneous solid lesion in the right lobe of the liver approximately $10 \mathrm{~cm}$ in diameter and this was confirmed by coeliac angiography. Liver biopsy confirmed the presence of a primary hepatocarcinoma with no associated cirrhosis. Because the presence of metastases would determine the mode of treatment a fibreoptic bronchoscopy was performed. No abnormality of the bronchial tree was seen but transbronchial biopsies from the right lower lobe showed cells closely resembling hepatocytes, confirming the presence of lung metastases from the primary hepatocarcinoma. The patient was given a course of doxorubicin which produces a clinical remission in $32 \%$ of patients with

Address for reprint requests: Dr D Honeybourne, Medical Registrar, King's College Hospital, Denmark Hill, London SE5 8RX.

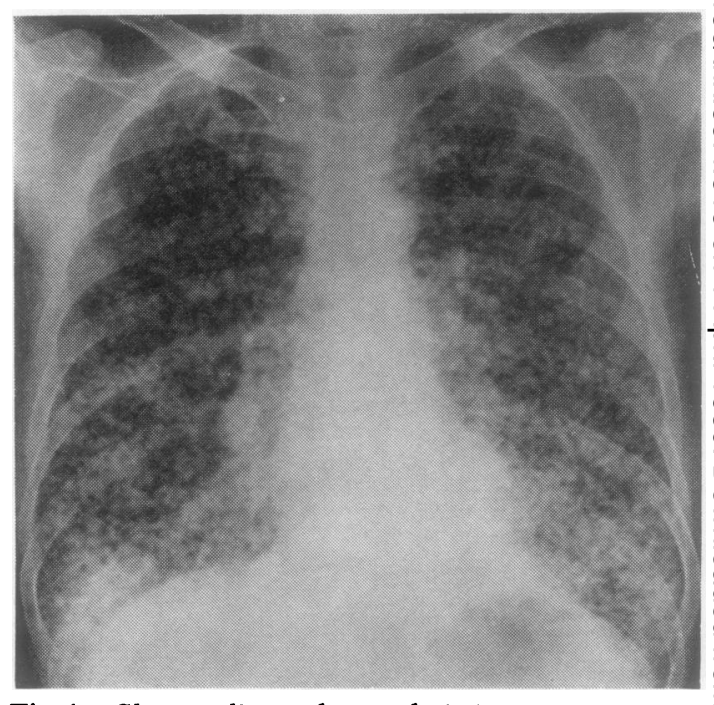

Fig 1 Chest radiograph on admission.

hepatocellular carcinoma. ${ }^{1}$ However, his clinical condition slowly deteriorated over the next three⿳亠丷厂 months, without change in his chest radiograph, and he died at home. A necropsy was not performed.

\section{Discussion}

Pulmonary metastases are common in patients with음 primary liver cancer. In one series ${ }^{2}$ they were present $D$ in $19 \%$ of such cases on admission to hospital and으․ appeared later in a further $6 \%$. However, at necropsy $52 \%$ of patients with primary liver carcinoma had evidence of pulmonary metastases, only half of $\mathrm{O}$ whom had radiological evidence of such metastases during life. In their series pulmonary metastases were often multiple, but unlike the case reported here the size of the metastases tended to be uniform for de particular patient, and rib metastases were very rare. $\mathbb{D}$

This case is unusual in that the chest radiographic appearance of widely disseminated amorphous illdefined circular shadows varying in size is much more commonly associated with metastases from a primary tumour of the prostate gland, thyroid, breast, or stomach, or results from the pulmonary lesions of a reticulosis or from intra-alveolar spread of aर bronchiolar adenocarcinoma. ${ }^{3}$ An underlying primaryo 


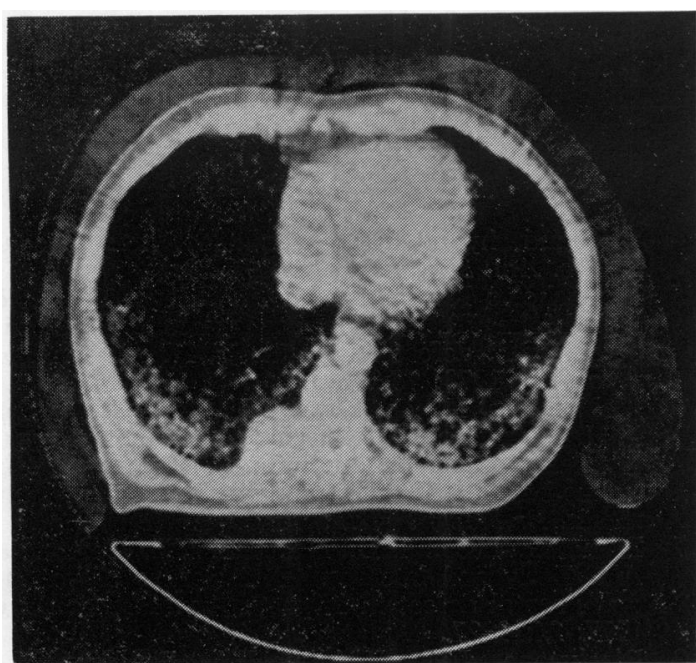

Fig 2 Computerised axial tomographic scan at the level of the eighth thoracic vertebra, viewed inferiorly. Reproduced by kind permission of Dr Jan de Winter, Royal Sussex County Hospital. hepatocarcinoma should be considered in the differential diagnosis of such a chest radiograph.

I am grateful to Dr P Hugh-Jones for permission to publish details of this patient.

\section{References}

1 Johnson PJ, Williams R, Thomas H, Sherlock S, Murray-Lyon IM. Induction of remission in hepatocellular carcinoma with doxorubicin. Lancet 1978; 1:1006-9.

2 Levy JI, Geddes EW, Kew MC. The chest radiograph in primary liver cancer-an analysis of 449 cases. S Afr Med J 1976; 50:1323-6.

3 Simon G. Principles of chest $X$-ray diagnosis. Fourth edition. London: Butterworths, 1978; 